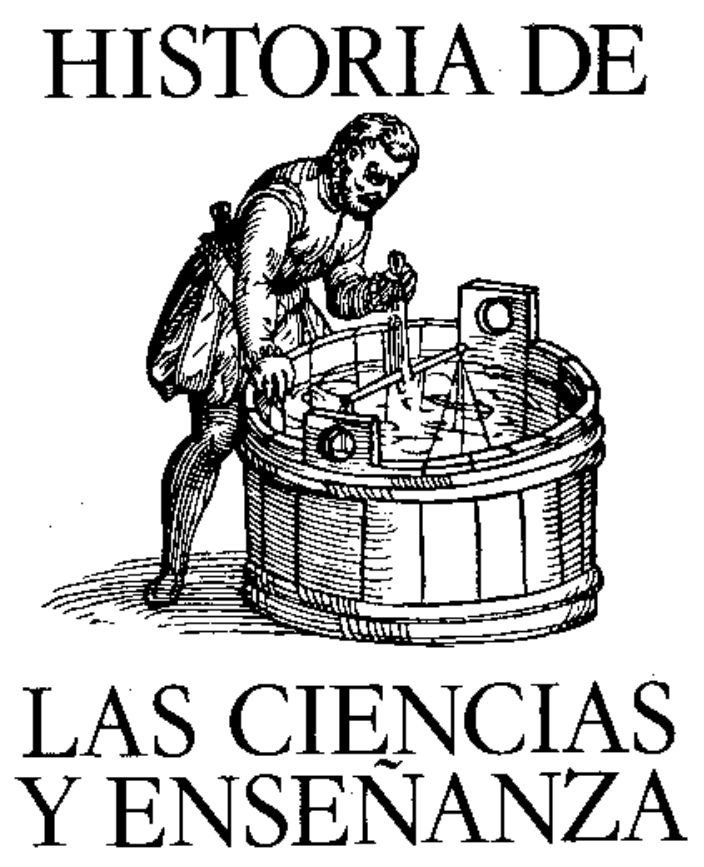

\title{
VER Y HABLAR COMO TOLOMEO Y PENSAR COMO COPÉRNICO
}

LANCIANO, N.

Departamento de Matemáticas. Universidad de Roma «La Sapienza»

Versión española de Pastor, C. y Carrascosa, J.

\section{SUMMARY}

No practical reasons exist to avoid in teaching Ptolemy's planetary model by suggesting the possibility of «seeing and speaking the way Ptolemy did» though we think as Copernicus.

\section{INTRODUCCIÓN}

No hay ninguna razón práctica para abandonar, o hacer abandonar en la educación, el modelo de Tolomeo, en la descripción de los movimientos de los cuerpos celestes.
Existen suficientes razones culturales respecto al lugar de la Tierra en el Universo para pensar que puede resultar útil, en el camino del conocimiento del mundo, ayudar a los jóvenes y a los adultos a «ver» el cielo con los ojos del modelo de Copérnico y Newton. 
A continuación me referiré a algunos caminos de la historia de la Ciencia y de la cultura y de los procesos de conocimiento individual que pueden conducir a utilizar ambos modelos, los modelos tolemaico y copernicano, sin que haya necesidad de elegir entre uno u otro para referirse a la misma realidad: la posición de la Tierra, del Sol y de otros cuerpos celestes, en el gran espacio del Universo en movimiento.

En el primer capítulo aclaro algunas bases sobre el problema, tanto desde un punto de vista astronómico, como respecto a la formación de los conceptos. Considero también algunos de los instrumentos propios de la relación entre conocimiento y representación del mundo externo, tales como nuestros sentidos y el lenguaje. En el capitulo "Como la enserianza presenta los modelos astronómicos» especifico algunas "caracterís" ticas) de la enseñanza que pueden inducir a dificulta. des en la percepción de la Tierra como planeta y del gran espacio del cosmos. El capítulo tercero to he dedicado a algunos momentos importantes de la historia de la ciencia, en relación con los problemas de la esfericidad de la tierra, los movimientos de rotación, $y$ de revolución y a renunciar a un centro único del mundo.

En el último capitulo insisto sobre el problema desde un punto de vista educativo a fin de dar algunas suge. rencias para ver lo que se piensa y pensar sobre lo que se ve.

\section{EL PRoblema astronómico $Y$ CONCEPTUAL}

"Yo me inclinaba a creer, como algunos de los más audaces de nuestros consejeros, que la Tierra participaba de determinados movimientos nocturnos y diur. nos de los que las santas procesiones de Eleusis son el simulacro más humano. En un mundo donde todo es un torbellino de fuerzas, danzas de átomos, donde todo está a la vez arriba y abajo, en la periferia y en el centro, yo no concebía la existencia de un globo inmó. vil, de un punto fijo que no estuviera al mismo tiempo en movimiento" (Yourcenar 1974).

\subsection{Los sentidos}

Nuestro punto de observación habitual para mirar la Tierra como planeta está sobre su misma superficie. En el caso de que la Tierra se moviese en el Universo, nosotros formaríamos un todo con ella, pero no seriamos conscientes de este desplazamiento. Para darnos cuenta de un movimiento utilizamos dos sentidos: la vista $\rightarrow$ los objetos que están alrededor de nosotros parecen moverse y la perspectiva de todo lo que nos circunda cambia-; y la percepción del equilibrio nuestro estómago y todo nuestro cuerpo se da cuenta de que se está en movimiento, cuando se camina, se corre, se va en automóvil o en ascensor. Para confirmar todo esto es necesario asegurarse de la relatividad del movimiento: los «tromps d'oeil» són fáciles y bien conocidos.

Esto es lo que le ocurre a la Tierra. Por lo tanto, es necesario encontrar un sistema de referencia externo a las cosas que se mueven, una con respecto a la otra, para decidir cuál es la que verdaderamente se mueve. El problema es complicado, ya que en el caso de la Tierra, todo puede parecer que se mueve: la Tierra, los planetas, las estrellas. Para basarse en el desequilibrio se necesita tener percepción, pero no es ésta la situación en los eventuales desplazamientos de la Tierra. Ninguna percepcion directa del cuerpo nos hace pensar en el desplazamiento de nuestro planeta sobre el que apoyamos los pies.

Además en los experimentos realizados a través de la historia, que analizaré seguidamente, para demostrar la hipótesis del movimiento de la Tierra, no hay «evidencias». No existen experimentos «cruciales» en el sentido de ser intuitivos para todos de forma inmediata (Acloque 1982). Sucede siempre, en estos experimentos, que el razonamiento interpone una distancia entre la percepción directa, base del pensamiento común, aunque desarrollado, y el pensamiento científico organizado.

\subsection{El lenguaje}

El lenguaje cotidiano, el lenguaje con el que los adultos, los niños, los periódicos y los libros se ocupan del Sol y de las estrellas se utilizan frases tales como: «EI 21 de marzo el Sol sale por el Este a las 6 de la mañana», "Sirio se pone..."

El lenguaje común, de un modo inconsciente, está ligado a una visión tolemaica, que traduce una visión de la Tierra inmóvil, alrededor de la cual el cielo y los astros giran cada 24 horas.

Nadie dice: «La Tierra ha girado para hacer visible el Sol, sobre el horizonte, en el Este». Nadie dice: "Sirio no será visible en cuanto la Tierra haya girado una hora más».

El mismo Copérnico escribe en el prólogo del Libro Segundo: «Nadie se maravilla si decimos que el Sol y los demás astros salen y se ocultan, o cosas parecidas, puesto que queda claro que lo decimos utilizando un lenguaje común que todos puedan comprender, no dejamos de tener presente que nosotros somos transportados por la Tierra, aunque la Luna y el Sol parece que nos adelantan, los astros vuelven después a su posición anterior y de nuevo vuelven a alejarse».

El lenguaje expresa el pensamiento, pero es necesario que, si la transformación del lenguaje que habria podido ser aceptada socialmente por la teoría copernicana no ha dado señales de producirse, quiere decir, que hay un hecho fundamental del pensamiento que no ha cambiado, o al menos, no se ha transformado total y adicalmente abandonando del todo lo que era antes. 


\subsection{Las evidencias y los modelos}

No hay ninguna razón práctica evidente para hacernos abandonar el modelo de Tolomeo.

Por el contrario, esto "funciona» estupendamente para explicar y describir lo que se ve cotidianamente.

Existen razones culturales para conocer, comprender y acoger el modelo de Copérnico-Newton. Son razones de "simplicidad" y de «belleza" del modelo, pero sobre todo es el principio de no considerar a la Tierra estática y en posición central con respecto a un Universo, en el que todo se mueve, y en el que no hay «un centro» lo que constituye el motivo más importante.

El egocentrismo, presente sobre todo en los niños, refuerza una idea tolemaica. La Tierra o mejor «mi ciudad», "yo mismo» constituye el centro inmóvil de todos los movimientos observados. La prueba de ello es lo que veo cada día y cada noche.

La percepción física del movimiento de los objetos en la Tierra demuestra que es mucho más fácil mover una cosa pequeña, ligera, que una cosa grande y pesada.

Pues bien, las estrellas y todos los objetos celestes parecen pequeños y ligeros, tanto es así que visiblemente parecen suspendidos en el cielo, mientras que la Tierra se nos presenta como grande y pesada.

No me paro a analizar los aspectos psicológicos que favorecen la idea de estabilidad de la Tierra sobre la que habitamos y de nuestra posicion en el centro del Universo, que juega en los individuos y en la colectividad un papel dominante.

En contra de todas estas «evidencias», algunos nos han dicho, desde pequeños, que la Tierra és esférica y que gira velozmente en torno a sí misma y en torno al Sol. Algunos aseguran que Copérnico «tiene razón» con respecto a Tolomeo.

Los niños de 4 o 5 años dicen que la Tierra se mueve y gira durante un año en torno al Sol. Pero, ¿qué piensan? ¿Cuáles son sus ideas y sus imàgenes más escondidas y profundas?

¿A qué edad, o mejor, en qué momento del conocimiento se produce la crisis y la necesidad de una elección entre los dos modelos opuestos?

Una elección que es una sustitución del modelo, una eleccion que en la historia ha sido difícil y combatida, que no ha sido secundaria, que no ha sido inofensiva para el pensamiento social, porque conduce a un cambio en el paradigma conceptual.

Una elección de estas características no puede tomarse sin dificultad por parte del pensamiento individual, desde un punto de vista afectivo, psicológico y cognoscitivo.

Me parece que se puede afirmar, a partir sobre todo de reflexiones sobre el lenguaje y el pensamiento adulto, que no se trata de realizar una elección que elimine una hipótesis para admitir otra: nadie deja de ser completamente tolemaico para hacerse simplemente copernicano. Se trata, más bien, de ser capaz y consciente de aceptar la posibilidad de mantener dos modelos diferentes, dos modelos de lenguaje para hablar de lo mismo: mantener la visión tolemaíca cotidiana y su relatividad con respecto a un sistema del mundo en el que todo se mueve y no exiten centros locales relativos. Se trata de descubrir la ductibilidad de nuestra mente y de ser capaces de hacer coexistir pensamientos diversos ante una misma realidad, por parte de nuestro pensamiento de adultos, alentados por la extraordinaria capacidad, que en este sentido, tienen los niños.

\subsection{Dilatar el Espacio}

Marguerite Yourcenar (1968) continua diciendo en "L'Oeuvre au noir» durante el proceso a Zenón: «EI sistema de Copérnico no estaba proscrito por la Iglesia, aunque los más escuchados por sus talares y togas moviesen la cabeza, con el aire de quien todo lo sabe, asegurando que no tardaría mucho tiempo en serlo, pero la aseyeracion que consistia en colocar al Sol, y no a la Tierra, en el centro del mundo, tolerada bajo el acuerdo de presentarlo como una tímida hipótesis, no dejaba de ofender a Aristóteles, La Biblia, y sobre todo a la necesidad humana de poner nuestro habitácuto en el centro del Todo. Es natural que una concepción que se distanciaba de la general evidencia del buen sentido no gustase al vulgo: sin sugerir otra, Zenón sabia que el concepto de que la Tierra se mueve, convulsionaba los hábitos que cada uno se ha construido para vivir. El mundo no era sólo la morada humana, y esta dilatación del espacio daba vértigo. Peor aún, el atrevimiento de sustituir la Tierra por el Sol, como centro de las cosas, la creencia en la infinidad de los mundos, que arrebata al mismo Sol el lugar de privilegio y niega la existencia de un centro aparecían para la mayoria de las mentes como una herejias.

\section{CÓMO LA ESCUELA PRESENTA LOS MO- DELOS ASTRONÓMICOS}

\section{1. «De un modelo a otro»}

Los caminos propuestos por la enseñanza y los libros pretenden, a veces, realizar en los alumnos el paso del modelo Tolemaico al modelo de Copernico; otras veces lo presentan el uno después del otro, como naturales recorridos históricos.

La idea de la historia de la ciencia que domina y sostiene este tipo de exposición es la idea de un camino lineal, en el que una idea más "precisa» de la realidad sucede a una idea más antigua y menos precisa, que sustituida por la nueva desaparece. Esta concepción, como muchos epistemologos han demostrado, no funciona para leer la historia de la ciencia, con respecto a la comprensión de los procesos de conocimiento, de formación de los conceptos científicos, de crecimiento 
de Ia capacidad de razonamiento, llegando a ser peligrosa por descaminada y embaucadora. Todo esto, en efecto, no da idea del dificil y controvertido camino, lleno de vacilaciones y de vueltas atrás del pensamiento individual.

Por todo lo dicho, mantengo que este supuesto «paso del sistema Tolemaíco al Copernicano» es ficticio, y el pensar en proponerlo nace de una reflexión inadecuada, ya sea sobre la historia de la ciencia, o sobre la construcción del pensamiento.

\subsection{La ausencia de observación directa}

En los libros de texto no suele existir ninguna propuesta de observacion directa de la realidad y del cielo, y hay algo, para mi, más grave, los libros «se expresan» como si los muchachos nunca hubieran hecho ninguna observación espontánea o razonada de los astros o del cielo con respecto al horizonte local, durante el día y la noche. A veces, algunos libros y programas no upreven' que los muchachos fuera de la escuela hacen experiencias del mundo que les circunda, del mundo que está encima y en torno a nosotros. A veces parece negarse todo esto, aunque se enseña.

La distancia entre el modelo y su representación por un lado, y la realidad modelizada por otro, no se recorre en los dos sentidos: de la realidad al modelo y del modelo a la realidad. Y esta desconexión puede durar mucho.

Un problema importante, tanto en la enserfanza de las matemáticas, como en la enseflanza de la astronomía. es el que está ligado a la visión espacial, a la capacidad mental de ver en tres dimensiones.

Las representaciones de los libros, las imágenes de video, las pizarras, etc. aplastan el espacio y no le dan dinamicidad (Braccesi y Balada 1980, Braccesi 1983).

A veces, para representar la Tierra se usa el mapamundi, y para representar el Sol un manantial de luz. También en este caso la representación viene hecha y dada desde el exterior.

\subsection{Dificultades inducidas}

Propongo, a continuación, algunos ejemplos de trabajos en los que se pueden ver las dificultades de los muchachos y adultos con respecto a los problemas de la forma y de los movimientos de la Tierra.

Conviene senalar antes que nada un elemento, a veces olvidado en el análisis de los procesos de aprendizaje, y que a mi manera de ver juega un papel importante en la enseñanza, la abundancia de nombres, números, cifras, propiedades, etc., es decir, la descripción de carácteres "estáticos", en Iugar de inducir a trabajar en la construcción de la capacidad para reconocer relaciones, y por lo tanto conceptos «dinámicos» entre los objetos.

Este tipo de dificultades es inducido y potenciado por actitudes concretas en las que el peligro está en creer que se conocen las cosas, cuando sólo se saben los nombres.

Este peligro se deriva de una determinada forma de enseñar, de un abuso de las imágenes televisivas, de renunciar a mirar con los propios ojos, a tocar, a recorrer los espacios y a utilizar nuestros sentidos para el conocimiento.

i) Muchos niños de la ciudad de Kaolak en Senegal, con una educacion de tipo francés, y con los que trabajé durante algunos días en enero de 1987, han dibujado, para mostrar el día y la noche, el globo terrestre con un objeto debajo del polo Sur (fig. 1). Ante mis preguntas se quedaban perplejos: «Lo llamamos Polo Sur» me decían. Preguntaba: ¿De que está hecho este objeto, de roca, de tierra...? No Io sabian, pero estaba. Ante mi invitacion a que dibujasen lo que ellos imaginaban, alguno habia reproducido el mapamundi con su soporte. Aquel objeto en el Polo Sur no era ni tierra, ní roca, isino plástico! La Tierra por lo tanto, en la imagen que la escuela había construido para ellos, no era ni esférica ni simétrica.

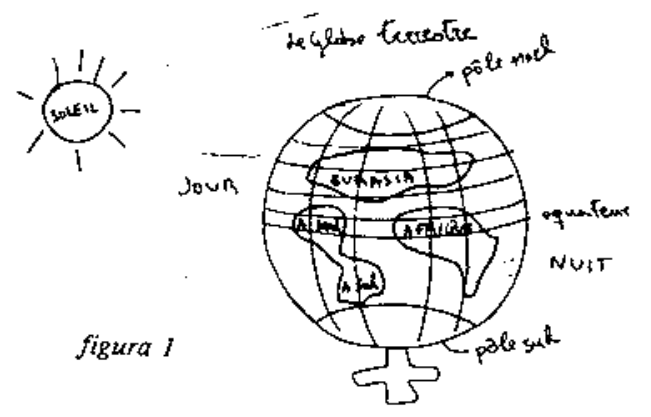

ii) Un muchacho de 13 años, Itraima Gassama, de la escuela de Louga en Senegal, ha hecho la figura 2 y me ha dicho: "La noche y el Sol están detrás de una montaña muy alta, por eso, nosotros no podemos ver el Sol, Cuando llega su hora, sale de detrás de la montaña y el día se hace. Cuando llega la hora de la Luna, el Sol se esconde detrás de la montaña y la Luna asciende y alumbra a la Tierra, en ese momento se hace de noche». Este niño, uno de los más despiertos intelectualmente del grupo, me ha subrayado: «Esto es así según mis ideas", $y$ ha añadido que si hubiese respondido de acuerdo con lo que ha aprendido en la escuela

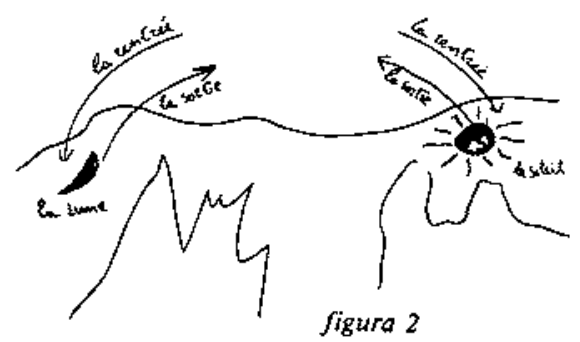

ENSENAANZA DE LAS CIENCIAS, 1989, 7(2) 
y en los libros habría contestado que «la noche y el Sol van al oeste", respuesta que, en efecto, han dado muchos de sus compañeros. La comprensión en una misma mente y en el mismo momento de dos ideas tan diversas me parece muy interesante para poder comprender las dificultades de los procesos del conocimiento (Lanciano 1987).

iii) La lucidez de la consciencia de Itrahima Gassama, que no renuncia a su elaboración personal, me ha recordado a un niño italiano de 10 años, Giancarlo, que había escrito "y después, por la noche, cuando miraba el espacio, me sentia un poco confuso, porque yo pensaba una cosa que no encajaba con las cosas que me había enseñado el maestro, y no sabía a quien dar la razón». Giancarlo había explicado la fatigosa y complicada experiencia constituida por el proceso de conocimiento.

iv) Para los niños más pequeños, los movimientos de los astros, del Sol y de la Luna son evidentes: «cuando yo ando la Luna y el Sol me siguen", "cuando voy en el coche con mi papa he visto que el sol nos seguias. Estas afirmaciones, a la edad de 4 o 5 años, pueden convivir sin entrar en conflicto con la idea de que uel Sol está quieto en el cielo». Es decir, en realidad no se mueve, pero si yo camino me sigue, y si me paro me espera. Estos niños ven en el Sol un compañero, un amigo fiel y silencioso y esta amistad puede no ser interrumpida ni negada por una escuela respetuosa que favorezca el encuentro con el verdadero cielo por un lado, y por el otro, saber escuchar a los niños, su imaginación y su pensamiento.

v) Para muchos adultos, las estrellas existen solo en el espacio que se encuentra en la parte de la Tierra opuesta al Sol (fig. 3). Por esta razón las vemos de noche.

Para otros, por el contrario, las estrellas se encuentran por todas partes, incluso en el espacio interplanetario. Para éstos, entre la Tierra y el Sol existen otras estrellas.

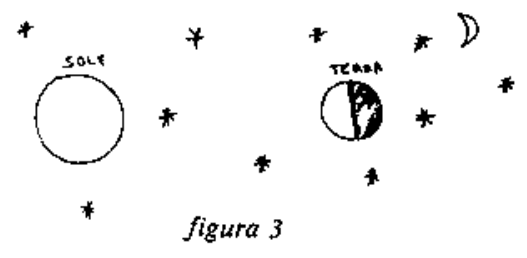

\section{EN LA HISTORIA DE LA CIENCIA}

En la historia de la ciencia y por lo tanto, en la imaginación colectiva, en un mundo como el occidental, don de la ciencia representa un mito reconocido y potente por la colectividad, los problemas relacionados con la forma de la Tierra y sus movimientos, han sido confrontados con experimentos y observaciones.
Llamo "experimentos» a las situaciones artificiales, creadas por el hombre como hipotesis para apoyar o impugnar una tesis. Llamo uobservación» a las situaciones que ofrece la naturaleza, en las que el hombre, si está atento, puede entender algo del funcionamiento del mundo, pero no influir sobre las cosas.

\subsection{La esfericidad de la Tierra}

En una teoría en la que la Tierra es uno de los planetas del Sistema Solar, su forma debe ser parecida a la de los otros planetas. Con los telescopios, las fotografías aéreas y las sondas espaciales todo esto se ha "visto».

La Tierra es todavia, para nosotros, un planeta muy singular.

En el año 1959 con las primeras fotos de la Tierra tomadas desde el espacio, que la mostraban «vista desde fuera), se ha realizado un salto en la vida de la humanidad, una especie de revolución mental.

Por primera vez, el hombre ha visto su "casa» desde fuera, desde lejos, entera, girando sobre sí, era en la realidad esférica, sin pedestal, como la Luna.

El ojo del hombre se habia alejado mucho por la demora para mirarla desde fuera, y en su totalidad. Era como haber cortado un cordón umbilical, ha escrito alguien, haber superado una distancia histórica.

Hoy la imagen nos es demasiado habitual para que estemos todavía en situación de maravillarnos, la vemos con demasiada frecuencia para mirarla con atención. Para los que han nacido después de que esta primera imagen se ha realizado, es obvio que ésa es la única inagen posible del planeta Tierra. Esta negligencia hace que se pierda la profundidad de la historia del pensamiento del hombre, sobre la forma de su planeta, sobre el modo de estar en el universo, de concebir su posición en el cosmos.

Es como si Atlante no hubiese sido ideado, es como si desde siempre, para el pensamiento del hombre, la esfera de la Tierra hubiese girado libre de vínculos y sin soportes, la misma Tierra que anteriormente se concebia plana, aislada del océano del mundo, sostenida por un dios o por un gigante, inmóvil en el centro de los movimientos.

Pero si el imaginario colectivo en las formas de mito o de ciencia puede prescindir de Atlante y acoger a $\mathrm{Co}$ pérnico para leer aquellas fotos del siglo $\mathrm{XX}$, el imaginario individual de los niños, y a veces de los adultos, crea otras imágenes mentales que no tienen ningún parecido con la realidad.

La metáfora del cielo según la cual «el cielo está encima de nosotros» y «el cielo está arriba» presupone la idea de la Tierra plana. Si reconstruímos la experiencia cotidiana tenemos la sensación de que más bien estamos apoyados sobre una base, que en la cima de una esfera. La Tierra esférica, planeta errante, cuerpo celeste tiene el cielo alrededor suyo, el cielo está en todas 
las direcciones, incluso debajo de nosotros; habitamos en el cielo.

No existe, por tanto, en el gran espacio, un sistema de referencia natural absoluto y preponderante con respecto Alto/Bajo, cada sistema de referencia es relativo.

En definitiva, me parece importante considerar que los esfuerzos hechos en la historia del pensamiento y las dificultades encontradas son de carácter simbolico, e incluso psicológico, y no sólo están ligadas a los medios técnicos utilizados para conocer y explorar el mundo. Cada uno pues, debe recorrer un camino y superarlo.

Indudablemente las imágenes y las filmaciones de las sondas espaciales pueden ayudar tanto a la intuición como al razonamiento, pero no pueden ser consideradas definitivamente por todos, como las imágenes de la Tierra que cada individuo construye para él mismo.

Escribe Plinio en la Historia Natural, en el verso 160 deI II Libro, acerca de la forma de la Tierra:

"Es grande la lucha entre la ciencia y la opinión popular, por un lado, se dice que los hombres están esparcidos en torno a la tierra, y que tienen los pies contrapuestos, y que para todos es parecido el zenit, y que por todas partes se camina estando a la vez en el centro de la Tierra. Por otro lado, se pregunta porque no caen nuestros antipodas, como si ellos, no tuviesen las mismas razones que nosotros para sorprenderse porque no caemos nosotros... Pero qué importancia puede tener esto, si existe otro enigma: la Tierra está suspendida y no cae junto a nosotros»; y en el verso 163 dice: "Hay un punto, sobre todo, en el que el pueblo da batalla, y es el relativo a que también el agua está amontonada en una forma convexa... Por la misma razón por la que desde las naves no se ve la tierra, cuando ésta es visible desde el mástił, y cuando un barquichuelo que se va alejando, si se le coloca un punto luminoso en el mástil da la impresión de que la luz baja poco a poco hasta desaparecer.

\subsection{La rotación de la Tierra}

Antes de Copérnico la hipótesis de que la Tierra estuviese en movimiento alrededor del Sol, y consecuentemente en rotación sobre sí misma, se sostuvo en varias ocasiones en la historia del pensamiento occidental.

Los Pitagóricos habian sostenido esta hipótesis, adversa a la física oficial de Aristóteles, y Aristarco di Samo, en el siglo III A.C., había esbozado un modelo heliocéntrico. Sostiene Alberto Elena (1986) que tales ideas fueron adversas por tres tipos de motivos:

i) Razones de indole religiosa: Plutarco escribe en el capitulo 6 del De facie in orbe lunare, cómo Cleante acusó de impio a Aristarco por haber desplazado la Tierra del "corazón del Universo».

ii) Razones de índole filosófica: El sistema heliostático era incompatible con la física aristotélica porque si la Tierra girase, y se moviese alrededor de su eje, las piedras no podrían caer perpendicularmente al suelo, las nubes deberian quedar detrás, y el lanzamiento de proyectiles seria distinto hacia el Este o hacia el Oeste. Todas estas observaciones son desmentidas por la experiencia cotidiana.

iii) Razones de índole técnica: Éstas fueron formula. das menos explicitamente, porque no contaban con el interés de las masas. De acuerdo con la hipótesis planetaria de Tolomeo, el radio del universo equivalía a cerca de 20.000 radios terrestres, lo que significa que el universo que concebían los antiguos era bastante pequeño. La rotación diaria debería haber producido un paralaje de 607 grados en las estrellas fijas, pero este fenomeno no se observaba.

Las observaciones y los experimentos para demostrar la rotación y la revolución de la Tierra pueden hacer referencias externas (los astros) e internas (la caída de los graves) y están ligadas, principalmente, a dos ramas de la física: la dinámica y la óptica.

Ninguno de los experimentos para «demostrar» el movimiento de rotación de la Tierra, es según mi opinión, intuitivo, ni crucial. S.E. Toulmin a propósito de los experimentos cruciales escribe: $« . .$. en las cuestiones teóriconcientíficas, ningún experimento singular pue. de ser perfectamente crucial, en el sentido lógico del término... No son, en efecto, las teorías las que hacen las previsiones sino los teóricos. Es decir, lo que un experimento prueba a nivel teórico depende, desde luego, de las interpretaciones que se le dan. De todos modos no se puede negar que un experimento sea "cruciai'. Puede ser crucial por ejemplo desde un punto de vista histórico, si determina cambios teóricos irrever. sibles.»

Sin una pretensión exhaustiva sełlaló algunas de las medidas y los experimentos efectuados, así como algunas observaciones de los fenómenos naturales que demuestran la rotación de la Tierra.

Entre estos experimentos se encuentran los siguientes: - el deslizarse de los fluídos

- el péndulo y el giróscopo de Foucault

- la caída de los graves y la disputa en relación a que los objetos deberian ser proyectados fuera de la tierra (Acloque 1982).

Entre las pruebas dinámicas de la rotación de la Tierra, en las que el movimiento de la Tierra provoca per. turbaciones sobre otras masas en movimiento, se encuentran algunas observaciones sobre el movimiento de los líquidos.

En cuanto al movimiento de los líquidos, se puede observar que en el agua que desciende en un lavabo for. mando un remolino, los círculos giran siempre en el mismo sentido, contrario al de las agujas de un reloj es decir, en el mismo sentido de la rotación de la Tierra en el hemisferio Norte y en sentido contrario, en el hemisferio Sur. En el Ecuador, el giro es en un 50\% 
en el sentido de las agujas del reloj, y en el otro $50 \%$ en el sentido contrario. La fuerza que interviene se lla. ma de Coriolys, pero la interpretación del fenomeno está relacionada con muchos axiomas que deben ser ad. mitidos por una teoría compleja sobre mecánica de fluidos.

Se pueden alegar, como ejemplos ulteriores de los efectos de la rotación de la Tierra, la erosión de una de las riberas de los rios, o el desgaste de una de las vías de las lineas ferroviarias.

Los experimentos de Foucault tienden a manifestar las perturbaciones ocasionadas por la rotación de la Tierra. Pero si las suyas fueron pruebas cualitativas, faltaba una prueba cuantitativa para mostrar que la ve. locidad de rotación de un plano de oscilación del péndulo está en relación con la velocidad de rotación terrestre.

Esta prueba es muy poco intuitiva. Comprender el experimento bajo la cúpula del Panteón de París implica una visión espacial muy compleja.

En el año 1852, Foucault presentó a la Academia su nuevo instrumento, cuyo nombre revela para qué ha sido inventado: "giróscopo», que viene del griego "giro-scopeo = enseñar el giro». Se trata de un instrumento fino y complicado. Probablemente el más «convincente» y «demostrativo».

En cuanto al tercer punto, la disputa vuelve a Tolomeo que había promovido una objección sobre la rotación de la Tierra, afirmando que Ios objetos, a causa de tal rotación, deberían de ser proyectados fuera de la Tierra. Copérnico para defencierse de esta objección seţalaba que De Rev, cap. 8: "Las cosas que son según la naturaleza producen efectos contrarios a las que surgen de la violencia. Las cosas que vienen conferidas a fuerza e impetu deben disolverse y no pueden subsistir por mucho tiempo, pero lo que es hecho por la naturaleza, está ordenado recte se habent y se mantiene en su mejor composición. Tolomeo se equivoca cuando teme que la Tierra y todas las cosas te. rrestres puedan dispersarse por una rotación causada por la naturaleza. Porque una cosa natural es completamente diferente del arte o de todo lo que puede rea lizar el ingenio humano.»

\subsection{El movimiento de revolución de la Tierra}

El movimiento de revolución de la Tierra ofrece «pruebas», quizás más intuitivas que el de rotación.

Por un lado se da el efecto de aberración de la luz de las estrellas que es bastante complicado, y el efecto de paralaje anual de las estrellas cercanas respecto a las estrellas lejanas, que es más intuitivo, y comprensible a partir de experiencias perceptivas de la vida cotidiana (Walusinski 1981). Copérnico y Galileo habían previsto un efecto de paralaje estelar, como consecuencia de las hipótesis heliocéntrica y del movimiento anual de la Tierra, pero los instrumentos ópticos de que disponían no permitieron observarlo.

Fue el astrónomo Bessel en el año 1838 quien midió el primer paralaje estelar: la estrella 61 Cygni, una de las estrellas más próximas a nuestra galaxia, que ya había sido observada regularmente desde hacia tiempo por el astrónomo Piazzi, en Palermo. Este paralaje media 0,31 segundos de arco y daba para la estrella una distancia de 3,3 parsec, esto es, cerca de II años luz.

Pero la observación de Bessel se benefició del trabajo que casi un siglo antes habia realizado el astrónomo Bradley, destacando un movimiento aparente de las estrellas, debido al error astronómico anual, de mayor envergadura que el derivado del paralaje.

El valor del error era, en efecto, de casi 40 segundos de arco en un anto, mientras que el máximo paralaje era de aproximadamente un segundo de arco.

\subsection{La pérdida del único centro}

Para apoyar la teoria copernicana era necesario desplazar la Tierra del centro del mundo; por otro lado, con respecto a los movimientos planetarios, era ya evidente que la Tierra no formaba un centro perfecto de Ios movimientos. Pero más que de un problema matemático o de concepción de cálculo, se trataba de un problema conceptual. ¿Era la Tierra, o no, el centro de algo?

Cuando Galileo vió a Júpiter, con el telescopio, y su sistema de cuatro satélites, afirmó que Júpiter consti. tuía el centro de los movimientos de aquellos cuatro cuerpos, y por lo tanto no era necesario referir todo a un único centro. La observación de que Júpiter era centro local de movimientos, permitía aceptar a la Tierra como centro del movimiento de la Luna, y reconocer la posición central del Sol, respecto a los movimientos de los planetas. En el pequeño Sistema Solar, los centros empezaban a multiplicarse.

El desquiciamiento de las esferas que la cultura euro. pea efectuó en el periodo de Copérnico y de Galileo permitió imaginar las estrellas distanciadas entre sí. Particularmente significativo es el diagrama con el que comienza la obra $A$ perfit description of the Caelestill Orbes de Thomas Digges (1545-1595). Las estrellas figuraban estar fuera del círculo de la octava esfera con distancias variables del centro del Universo. La leyenda indica que algunas de estas estrellas son mucho más grandes que el Sol y se reparten aleatoriamente por to. do el espacio infinito. Sin duda, ia fuente de Digges es la obra de Palingenus (1500-1543).

\section{ALGUNAS SUGERENCIAS PARA VER LO QUE SE PIENSA, Y PENSAR EN LO QUE SE VE}

Una visión del espacio cósmico lleva consigo una visión de la posición de la Tierra con respecto al Sol, a 
los planetas y a las estrellas, es decir, nuestra situación en el Universo.

Para construir el concepto de espacio cósmico con respecto a la Tierra, ya sea desde la Tierra, ya sea imaginando que se la mira desde fuera, es necesario, o al menos útil, haber realizado algunas experiencias y reflexiones. Propongo algunas, que me parecen importantes y que pueden ayudar a ver lo que la mente piensa y a pensar en lo que los ojos ven.

\subsection{La importancia de la posición del observador}

Es evidente la importancia del punto escogido para observar un fenómeno que se desarrolla en el tiempo y en el que un objeto recorre un espacio. Observar una cosa desde arriba o desde abajo, desde la derecha o la izquierda, repetir los gestos de alguien que está en frente, observar sin cambios el punto de observación son pequeñas pruebas que pueden convencernos.

La posición del cuerpo si estamos de pie o de espaldas, o tendidos sobre un lado, puede darnos percepciones distintas, por ejemplo, del vuelo de un pájaro.

Cambiar nuestro punto de observación puede variar la línea del horizonte, de tal manera que el Sol ya oculto para un observador, puede para otro, estar todavia sobre el horizonte.

\subsection{La importancia del sistema de referencia}

La elección consciente de un sistema de referencia y su reconocimiento es fundamental para la descripción de cualquier fenómeno dinámico. Son đisposiciones necesarias para poder pasar de una referencia a otra, para describir las cosas desde dentro o desde fuera, para considerar los fenómenos y los movimientos en su relatividad.

Para enseñar las estrellas se puede usar un sistema de coordenadas «locales», como el que está basado en el horizonte y la altura a éste, válido localmente en base a las propias coordenadas geográficas, o un sistema de coordenadas «absolutas», válidas en cualquier punto de la Tierra, basado sobre el Ecuador Celeste y la distancia desde éste.

\subsection{La profundidad del cielo estrellado}

El cielo estrellado no es una esfera con puntos luminosos engarzados o con agujeros en los que penetra el fuego que se encuentra más allá de esta esfera, más bien, lo que vemos es un espacio con manantiales luminosos situados a distancias muy variables entre ellos y entre la Tierra; va desde algunos años luz, hasta millones de años luz.

Es nuestra percepción visual la que nos hace suponer las estrellas como si todas estuvieran a la misma distancia. El uso de los planetarios, de los globos celestes, de los mapas celestes puede sugerir y consolidar esta visión falsa, si no se pone atención en la presentación a los usuarios.
Como es difícil percibir con la mirada la profundidad del cielo en todas las direcciones del espacio, ésta puede ser evocada por la mente.

Las distancias estelares no se expresan con la unidad de medida de longitud, sino con los tiempos de recorrido de la luz desde un objeto celeste hasta nosotros.

Puesto que la velocidad de la luz en el vacío es constante, el tiempo empleado para recorrer un determinado espacio es proporcional al espacio recorrido. La estrella Sirio que está a 8 años luz de la Tierra, es cuatro veces más próxima que la estrella Arturo que está a 35 antos luz.

Para conocer las distancias de las estrellas se puede comparar entre ellas y con los tiempos de nuestra vida. Para las distancias mayores se recurre a los acontecimientos históricos y a la historia del planeta Tierra.

La imagen de Sirio que vemos hoy ha «salido» de $\mathrm{Si}^{-}$ rio cuando nacian los niños que ahora tienen ocho años, ha viajado durante todo este tiempo a una velocidad de $300.000 \mathrm{~km} / \mathrm{s}$, por el espacio interestelar para llegar a nuestros ojos.

El cielo de los antiguos era "pequeño", porque la esfera de las estrellas fijas se suponía a una corta distancia del centro del mundo, y porque se pensaba que todo el cielo era lo que se podia reunir con una mirada. Durante mucho tiempo, para la tradición cultural más difundida, todo lo que "no era visible», "no existia». El cielo sondeado con el telescopio y otros receptores de ondas electromagnéticas, incluso fuera de la banda de lo visible, se ha dilatado enormemente por la gran cantidad y variedad de sus objetos.

\subsection{La observación directa del cielo}

Para trabajar sobre estos elementos encuentro que la observación directa del cielo, de sus objetos y de sus fenómenos, tanto de noche como de día es fundamental e insustituible.

Y por la experiencia de la observación directa, palabras como: alba, tramontana, constelación, polo norte coincidente con la estrella Polar, Eclíptica y Ecuador celeste pueden tomar cuerpo y clarificar el pensamiento, habiéndose introducido a través de los ojos.

Si se utiliza el observatorio privilegiado de la Astronomia, que es el cielo, la verdadera naturaleza y no sus imágenes, muchas cosas se nos presentan más claras y menos complejas.

Los elementos de la tridimensionalidad del espacio, la esfericidad de los objetos, la circularidad de los movimientos y su carácter continuo, la verdadera duración de los fenómenos, cuando en parte o en su totalidad son observados directamente, pueden ser una base de conocimiento mucho más sólida, estable e intuitiva que las figuras, los discursos, los nombres e incluso los modelos. 
Por otro lado, en el caso particular de la Astronomia, el estupor, la capacidad de asombro de cada uno ante la belleza y la grandiosidad del cielo pueden constituir la base para desear conocer, saber, estudiar o para gozar al máximo. La profundidad del cielo, dentro del espacio vacio; que nos circunda y en el que estamos inmersos se evoca mejor con un cielo estrellado, que con una lección en la pizarra. Evocar, quiere decir sugerir a la mente, ayudar a comprender, a penetrar.

Frecuentemente las experiencias escolares muestran que si se recibe información sin plantear ningún problema, sin formular hipótesis, sin preguntas, probablemente no se llegará a retener y a reelaborar la información recibida.

La escuela, con demasiada frecuencia, aporta un gran número de nociones, de nombres sin haber creado el problema, de esta manera no se elabora conocimiento, no se dota de los verdaderos instrumentos para emprender un camino de conocimiento.

Por todo to expuesto se ve que no es fácil deducir si el modelo válido para describir la realidad es el de Tolomeo o el de Copérnico, si la Tierra se mueve o no, $y$ si es un centro o no.

Se puede, de todos modos, proponer a los muchachos un modelo heliocéntrico, e intentar utilizarlo desde un punto de vista didáctico, ya sea por medio de la observación directa, ya sea por los elementos teóricos o mediante algunos conocimientos básicos sobre Astronomía.

\subsection{El nacimiento de un problema: el movimiento de los planetas}

¿Por qué Copérnico ideó una nueva organización del mundo? ¿Por qué el sistema de Tolomeo, en el año 1500 , estaba en crisis?

La memoria sinoptica de los antiguos, como la define Giorgio de Santillana (1985), es capaz de acercar en la mente objetos y acontecimientos lejanos en el espacio y en el tiempo, que permiten conectar diversas imágenes del cielo producidas en momentos diferentes.

Marco, un niño de 11 años, reprodujo en un dibujo, algunos objetos luminosos que vió en el cielo, una tarde después de la puesta del Sol. Luego, rehizo con mucho cuidado, el dibujo durante cuatro dias consecutivos, mirando en la misma dirección. ¿Qué es lo que había cambiado?

La Luna no estaba a la misma hora en el mismo lugar del cielo, ni respecto al horizonte, ni respecto a las estrellas. Tampoco un objeto con una luminosidad más fuerte, pero no destelleante como las otras estrellas, estaba en el mismo lugar del cielo. Como la Luna, aquel objeto se desplazaba.

Marco ha descubierto los planetas y los ha visto "errar» por el cielo. La palabra planeta viene del griego planao $=$ ir errando. Algunos cuerpos celestes se distin- guen por cambiar de posición con respecto a las estreIlas fijas, que recorren el cielo sobre el horizonte, todas juntas y con la misma configuración, y que pueden reunirse en constelaciones.

El problema de reunir todos los cuerpos celestes en un único sistema del mundo, dar una organizacion fisicogeométrica del cosmos, nace de la observación y de! registro repetidos, constantes y atentos de los fenómenos del cielo. Existen 5 cuerpos celestes además del Sol y la Luna, visibles a simple vista, que se desplazan según su propio ritmo, a lo largo de un camino similar a un gran círculo del cielo, la Eclíptica, la via de los planetas.

Quizás el origen de la percepción de los movimientos del cielo fue la capacidad de los antiguos para reunir observaciones hechas en tiempos distintos y en espacios diferentes gracias a una memoria sinoptica, hoy perdida, por no haber sido practicada. Tal memoria habría permitido, pues, relacionar entre sí varias imágenes del cielo producidas en momentos diferentes.

Esta memoria, relacionada con la mirada y visualización de los fenómenos, se ha ido desarrollando cada vez menos, mientras la escritura y el registro escrito se afirmaban, y por lo tanto la garantía de memoria venía confiada a un objeto externo a la mente de los hombres.

\subsection{Algunas metas alcanzadas}

Como consecuencia de mirar el cielo y observar los planetas visibles nocturnos, durante cerca de dos años, los niños de $V$ elemental han expresado su deseo de estudiar los planetas en los libros. El estudio de Júpiter tomaba cuerpo en la mente de Salvador, porque lo había visto en muchas citas nocturnas, lo había seguido en su movimiento entre las estrellas, y lo habia reconocido al compararlo con otros planetas.

Un día seguíamos la sombra de un palo en el patio, tratando de pintar el pavimento, que poco a poco era invadido por la sombra, y estábamos maravillados por Ia velocidad con que la sombra se desplazaba, lo que hacía difícil marcarla en la tierra. En este momento, Salvador observó "Mira si hubiésemos estado en Jípiter hubiera sido aún peor».

Salvador sabia que Júpiter gira sobre sí mismo en ocho horas, pero sobre todo habia comprendido de forma radical que la sombra se desplaza porque la Tierra gi$r a$ y sabia concretar este conocimiento en un contexto nuevo. Este ninto me ha enseñado algo sobre como mirar el mundo y ha demostrado cuáles eran sus conocimientos, que le permitían hacer estas relaciones. Un conocimiento de tipo "dinámico» en el que la Tierra pertenece al mundo de los planetas.

Salvador, con su inteligencia "visionaria» indispensable para la geometría y para comprender los movimientos de los cielos, veia el movimiento de la Tierra. 
$\mathrm{El}$ año pasado, los niños tenían como trabajo para casa mirar Júpiter, Venus y Marte por el Oeste, a la puesta del sol. Una mañana Estéfano Ilega todo alborotado a clase diciendo: «Maestro ayer me sucedió una cosa estraña, una cosa particularisima». Ayer me dí cuenta que estaba situado en un planeta y que también yo giraba en el espacio como Júpiter, Venus y Marte».

Pienso que el mirar, el mirar a lo lejos y con atención, puede desarrollar un órgano de percepción directa.
Es una visión amplia del espacio la que estos niños manifiestan haber construido y poseer.

En su «geometria cósmica» la Tierra es una esfera en movimiento y no tienen miedo, el cielo es para ellos la verdadera morada de los hombres.

Una elección que nos conduce a un cambio de modelo, una elección que a lo largo de la historia ha sido combatida, no ha resultado ser secundaria, ni inofensiva para el pensamiento social, porque conduce a un cambio del paradigma conceptual.

\section{REFERENCIAS BIBLIOGRÁFICAS}

ACLOQUE, P., 1982. Histoire des expériences pour la mise en evidence du mouvement de la Terre, Cahiers d'histoire et de philosophie des Sciences, Vol. 4.

BRACCESI, A., 1983. Un dimenticato esperimento crucis: la prova fisica della rotazione terrestre ottenuta nel 1971 da G.B. Guglielmini osservando la desviazione a Sud Est della verticale del gravi in caduta libera, Giornale di $\mathrm{As}$ * tronomia, Vol. 9(4), pp. 319-332.

BRACCESI, A. y BALADA, A., 1980. Proseguendo sulla Specola di Bologna..., Giornale di Astronomia, Vol. 6(1).

EleNA, A., 1986. Nicolas Copernico. Thomas Digges. Galileo Galilei. Opuisculos sobre el movimiento de la Tierra. (Alianza Editorial: Madrid).

LANCIANO, N, , 1987. Au Sénégal entre Soleil et Lune. Cahière Clairaut, Vol. 38, pp. 15-18.

PLINIO IL VECCHIO, Historia Naturalis. Toulmin S.E. Esperimenti cruciali: Priestley e Lavoisier. Radici del pensiero scientifico, a cura di Wiener P.P. e Noland A. (Feltrinelli: Milano).

SANTILLANA, G. DE, 1985. Fato antico e fato moderno. (Adelphi: Milano).

WALUSINSKI, G., 1981. Ciel passé présent. (Études vivantes: Paris).
YOURCENAR, M., 1968. L'oeuvre au noir. (Gallimard: Paris).

YOURCENAR, M., 1974. Mémoires d'Hadrien. (Gallimard: Paris).

\section{OTRA BIBLIOGRAFIA}

LANCIANO, N., 1983. Dall'esperienza a! modello in Astronomia. Didattica delle Scienze. Vol. 103, pp. 14-21.

LANCIANO, N., 1986. Weeks of Astronomy in the countryside, GIREP Conference 1986. COSMOS An educational challenge,, edited by ESA, pp. 211-215.

NUSSBAUM, J., 1986. Student's perception of astronomical concepts. GIREP Conference 1986. COSMOS An educational challenge, edited by ESA, pp. 87.

NUSSBAUM, J. y SHARONI, N., 1983. Changes in second grade children's preconception about the earth as cosmic body. Science Education, Vol. 67(1), pp. 99-114.

ZLLSEL, E., Copernico e la meccanica, Radici del pensiero scientifico a cura di Wiener P.P. e Noland A. (Feltrinelli: Milano). 